\title{
PROCESSO COMBINADO DE COAGULAÇÃO/FLOCULAÇÃO E OZONIZAÇÃO PARA TRATAMENTO DE MANIPUEIRA
}

\author{
G. V. LEON ${ }^{1}$, J. C. ZENI ${ }^{1}$, V. LEIFELD² e L. IGARASHI-MAFRA ${ }^{1,2}$ \\ ${ }^{1}$ Universidade Federal do Paraná, Departamento de Engenharia Química \\ ${ }^{2}$ Universidade Federal do Paraná, Programa de Pós-Graduação em Engenharia de Alimentos \\ E-mail para contato: gabvleon@gmail.com
}

\begin{abstract}
RESUMO - A manipueira é um resíduo líquido que corresponde à água de constituição da mandioca retirada na prensagem da raiz. Apresenta característica leitosa, alta carga orgânica e cianeto em sua composição. Além disso, é um efluente resistente a tratamentos convencionais. Uma alternativa é a combinação de diferentes tipos de tratamentos, incluindo os Processos Oxidativos Avançados (POAs). Sendo assim, o objetivo desse trabalho foi avaliar a degradação da manipueira pelos processos combinados de coagulação/floculação seguido do processo de ozonização. Os experimentos consistiram em coagulação/floculação pH 6,0 e 1200 mg L-1 de cloreto férrico, e no processo de ozonização, houve a variação de $\mathrm{pH}$ e de concentração de ozônio na amostra pós-coagulação. As análises realizadas para controle dos processos foram turbidez, Demanda Química de Oxigênio (DQO) e análise espectrofotométrica (200-800nm). Os resultados obtidos apontam elevada redução da turbidez, DQO e cor do efluente.
\end{abstract}

\section{INTRODUÇÃO}

Nos últimos anos, com o aumento populacional, cresceu também o número de indústrias alimentícias e, consequentemente, a quantidade de resíduos descartados em rios, que geram impactos ambientais.

Uma dessas indústrias é a de farinha de mandioca, que no seu processo de fabricação gera subprodutos problemáticos devido suas elevadas cargas orgânicas, efeito tóxico e grandes vazões - para cada tonelada de raiz gera-se em torno de $0,25 \mathrm{~m}^{3}$ de manipueira - por vezes não tratados adequadamente e lançados no ambiente (Nasu et al., 2010). A poluição gerada por ele se compara àquela produzida por 200 hab/dia (Souza et al., 2014).

A manipueira corresponde à água de constituição da raiz retirada na prensagem da mandioca ralada no processo de fabricação da farinha (Cereda, 2001). Tem aspecto leitoso e é composto por 5 a $7 \%$ de fécula, proteínas, glicose, restos de células, ácido cianídrico, bem como outras substâncias orgânicas e nutrientes minerais essenciais (Kuczman et al., 2007).

Visto que este resíduo é tão prejudicial ao meio ambiente e de difícil tratamento, é de suma importância que se encontre um sistema de tratamento que reduza essa carga orgânica. 
Uma proposta é a associação da coagulação/floculação com o processo oxidativo avançado de ozonização.

Os Processos Oxidativos Avançados (POA's) são um conjunto de tecnologias promissoras para o tratamento de contaminantes persistentes e tóxicos, baseados na geração de radicais livres, em especial o radical hidroxil $(\cdot \mathrm{OH})$. Este radical reage rápida e indiscriminadamente com muitos compostos orgânicos de diferentes formas, podendo até mesmo promover a completa mineralização das substâncias orgânicas, transformando-as em $\mathrm{CO}_{2}$, água ou moléculas mais simples (Melo et al., 2009).

Um desses processos (ozonização) utiliza o ozônio $\left(\mathrm{O}_{3}\right)$ por ser um oxidante energético e não tóxico. Sua reação pode ocorrer através de mecanismo direto (reação eletrofílica), ou mecanismo indireto (através do radical livre hidroxil, formado a partir da decomposição do ozônio) (Melo et al., 2009).

$\mathrm{O}$ primeiro caso acontece com átomos com uma densidade de carga negativa $(\mathrm{N}, \mathrm{P}, \mathrm{O}$ ou carbonos nucleofílicos), ou com ligações duplas ou triplas do tipo carbono-carbono e nitrogênio-nitrogênio, além disso, é favorecido em meios ácidos (Fioreze et al., 2014).

Já quando a reação acontece por meios radicalares (indireto), é chamada de POA propriamente dita e tem a capacidade de reagir com os compostos orgânicos de $10^{6}$ a $10^{12}$ vezes mais rápido que o ozônio (Fioreze et al., 2014).

Assim, o objetivo deste trabalho foi avaliar a potencialidade da combinação do processo físico-químico de coagulação/floculação com a ozonização para a redução do potencial poluente da manipueira.

\section{MATERIAIS E MÉTODOS}

No processo de coagulação/floculação e ozonização da manipueira, utilizou-se o efluente real da produção de fécula de mandioca de uma empresa da região norte central paranaense. A água utilizada no preparo de cada solução foi água destilada. Os reagentes utilizados no ajuste de $\mathrm{pH}$ para cada solução foram de grau analítico P.A. Para o ajuste inicial do $\mathrm{pH}$, utilizou-se hidróxido de sódio $\left(\mathrm{NaOH}, 6 \mathrm{~mol} \mathrm{~L}^{-1}\right)$ ou ácido sulfúrico $\left(\mathrm{H}_{2} \mathrm{SO}_{4}, 0,1 \mathrm{~mol}\right.$ $\mathrm{L}^{-1}$ )

A coagulação/floculação foi conduzida em béquer com $10 \%$ (v/v) da solução coagulante (1200 mg L $\mathrm{L}^{-1}$ de $\mathrm{FeCl}_{3}$ ) e manteve-se sob agitação por 10 minutos. Em seguida, foi adicionado $2 \%(\mathrm{v} / \mathrm{v})$ de polímero catiônico (agente floculante) e mantida agitação lenta por mais 5 minutos. Por fim, a amostra foi filtrada. As condições da coagulação foram obtidas em experimentos prévios (dados não apresentados).

A configuração experimental para o tratamento das amostras com o ozônio consistiu em um gerador de ozônio e um reator encamisado. O ozônio era gerado por um ozonizador (Philozon $\mathrm{O}_{3} \mathrm{R}$ modelo ID-10, Balneário Camboriú, Brasil) e sua injeção foi feita com auxílio de uma mangueira, a qual possuía uma ponta difusora de ar, sendo que foram injetados 
constantemente $1 \mathrm{~L} \mathrm{~min}^{-1}$ de ozônio. O tanque de reação apresentava capacidade de $250 \mathrm{~mL}$, e estava sob constante agitação magnética a fim de manter homogênea a dispersão do ozônio.

Para adequar as melhores condições do tratamento da manipueira, foi realizado um planejamento experimental $2^{2}$, com três repetições no ponto central, variando-se o $\mathrm{pH}$ e a concentração de ozônio. Por isso, antes de iniciar cada reação, foi ajustado o pH da amostra de acordo com a tabela 1.

Tabela 1- Planejamento experimental da ozonização.

\begin{tabular}{|c|c|c|}
\hline Experimento & $\mathrm{pH}$ & {$\left[\mathrm{O}_{3}\right](\%)$} \\
\hline 1 & 3,0 & 10 \\
\hline 2 & 9,0 & 10 \\
\hline 3 & 3,0 & 50 \\
\hline 4 & 9,0 & 50 \\
\hline 5 & 6,0 & 30 \\
\hline 6 & 6,0 & 30 \\
\hline 7 & 6,0 & 30 \\
\hline
\end{tabular}

Em seguida, coletou-se alíquotas em intervalos de 2,5 min nos 10 primeiros minutos, de 5 min no intervalo de 10 a 30 minutos, de 10 min até os 80 minutos de reação e por fim de 20 minutos até completar duas horas de reação. Essas alíquotas foram utilizadas para análise por varredura no espectrofotômetro ProAnálise (UV 6100PC), de turbidez (turbidímetro) e para posterior análise de DQO, medida seguindo o método de colorimetria de refluxo fechado, segundo descrito em APHA (1998). Por último, mediu-se o pH final da amostra tratada.

\section{RESULTADOS}

Os resultados das análises de turbidez e DQO durante e após o processo de ozonização estão apresentados na Figura 1. Pôde-se perceber que a redução da carga orgânica foi limitada devido a baixa eficiência na mineralização dos mais variados componentes orgânicos (Almeida et al., 2004). Entretanto, a ozonização teve grande influência na redução da turbidez, que chegou a 85\% (na amostra 5 de pH 6,0 e concentração de ozônio de 30\%).

Os valores de pH finais para cada uma das amostras estão relacionados na Tabela 2.

Tabela 2- Valores de $\mathrm{pH}$ finais.

\begin{tabular}{|l|c|c|c|c|c|c|c|}
\hline Amostra & 1 & 2 & 3 & 4 & 5 & 6 & 7 \\
\hline pH final & 2,98 & 6,83 & 3,05 & 6,42 & 5,44 & 5,20 & 4,71 \\
\hline
\end{tabular}


Figura 1- Resultados de DQO e turbidez para (a) $\mathrm{pH} 3,0$ e $\left[\mathrm{O}_{3}\right]=10 \%$; (b) $\mathrm{pH} 9,0$ e $\left[\mathrm{O}_{3}\right]$ $=10 \%$; (c) $\mathrm{pH} 3,0$ e $\left[\mathrm{O}_{3}\right]=50 \%$; (d) $\mathrm{pH} 9,0$ e $\left[\mathrm{O}_{3}\right]=50 \%$; (e), (f) e (g) $\mathrm{pH} \mathrm{6,0} \mathrm{e}\left[\mathrm{O}_{3}\right]=30 \%$;
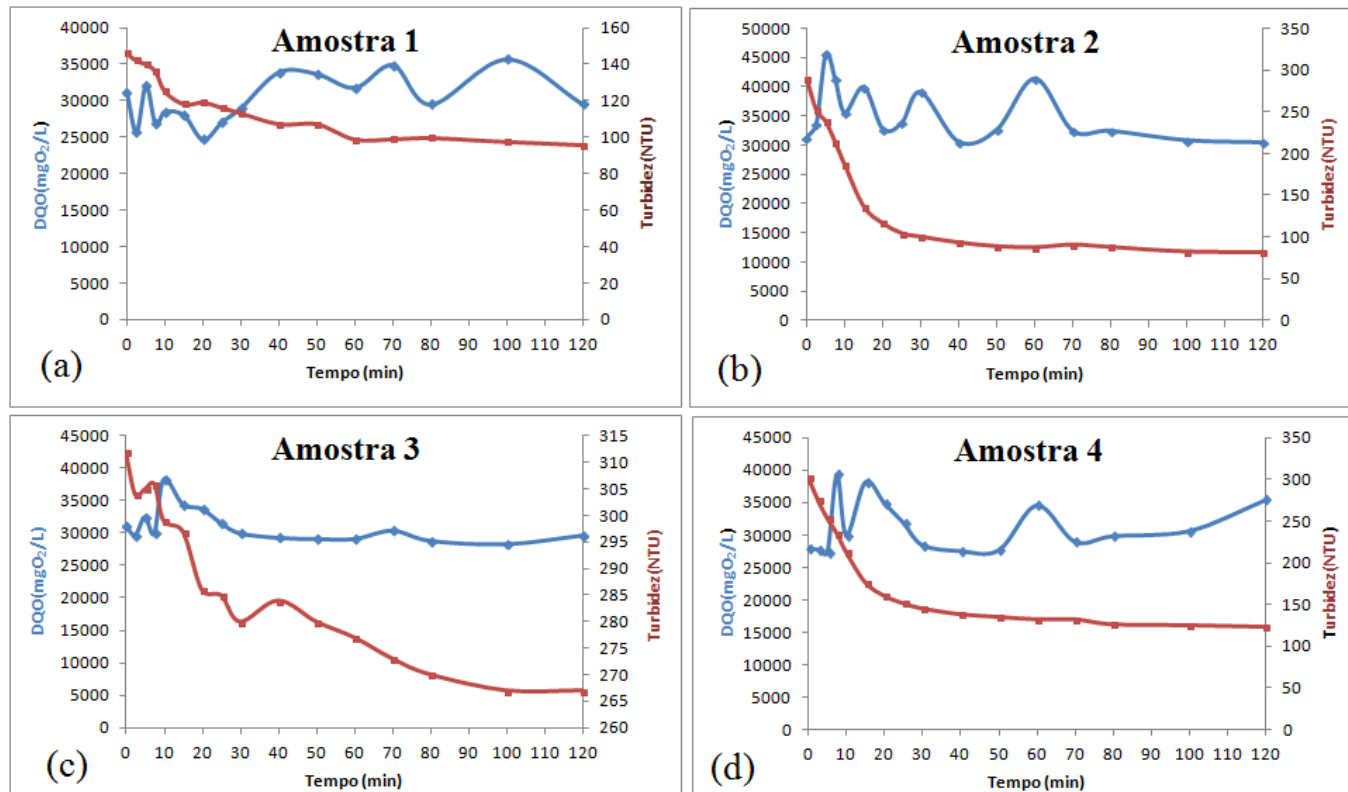

(b)

Tempo (min)
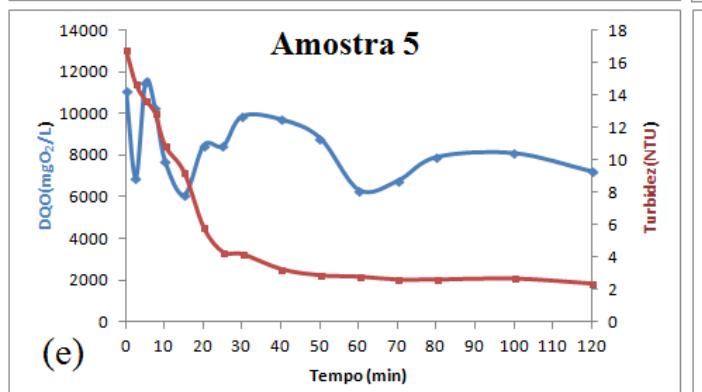

(d)

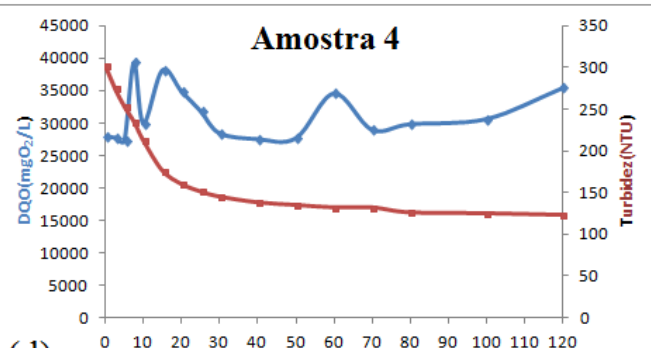

Tempo (min)
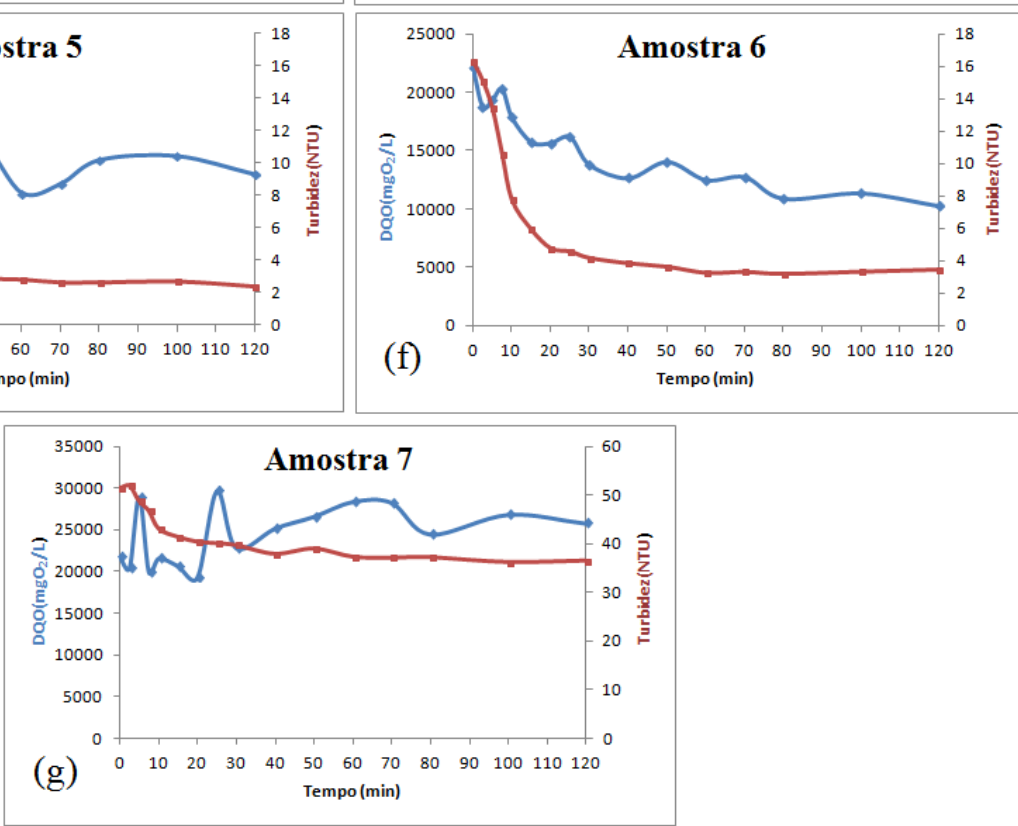

Além disso, é possível verificar pelas varreduras espectrais (Figura 2) que houve redução no parâmetro $\mathrm{A} / \mathrm{A}_{0}$ no decorrer das duas horas de reação. Na literatura, o ozônio é tido como um dos agentes oxidantes mais efetivos para a remoção de cor dos efluentes, pelo potencial de degradação dos grupos cromóforos presentes nas águas residuárias (Almeida et al., 2004). 
Figura 2- Varreduras para (a) $\mathrm{pH} 3,0$ e $\left[\mathrm{O}_{3}\right]=10 \%$; (b) $\mathrm{pH} 9,0$ e $\left[\mathrm{O}_{3}\right]=10 \%$; (c) pH 3,0 e $\left[\mathrm{O}_{3}\right]=50 \%$; (d) $\mathrm{pH} 9,0$ e $\left[\mathrm{O}_{3}\right]=50 \%$; (e), (f) e (g) $\mathrm{pH} 6,0$ e $\left[\mathrm{O}_{3}\right]=30 \%$;
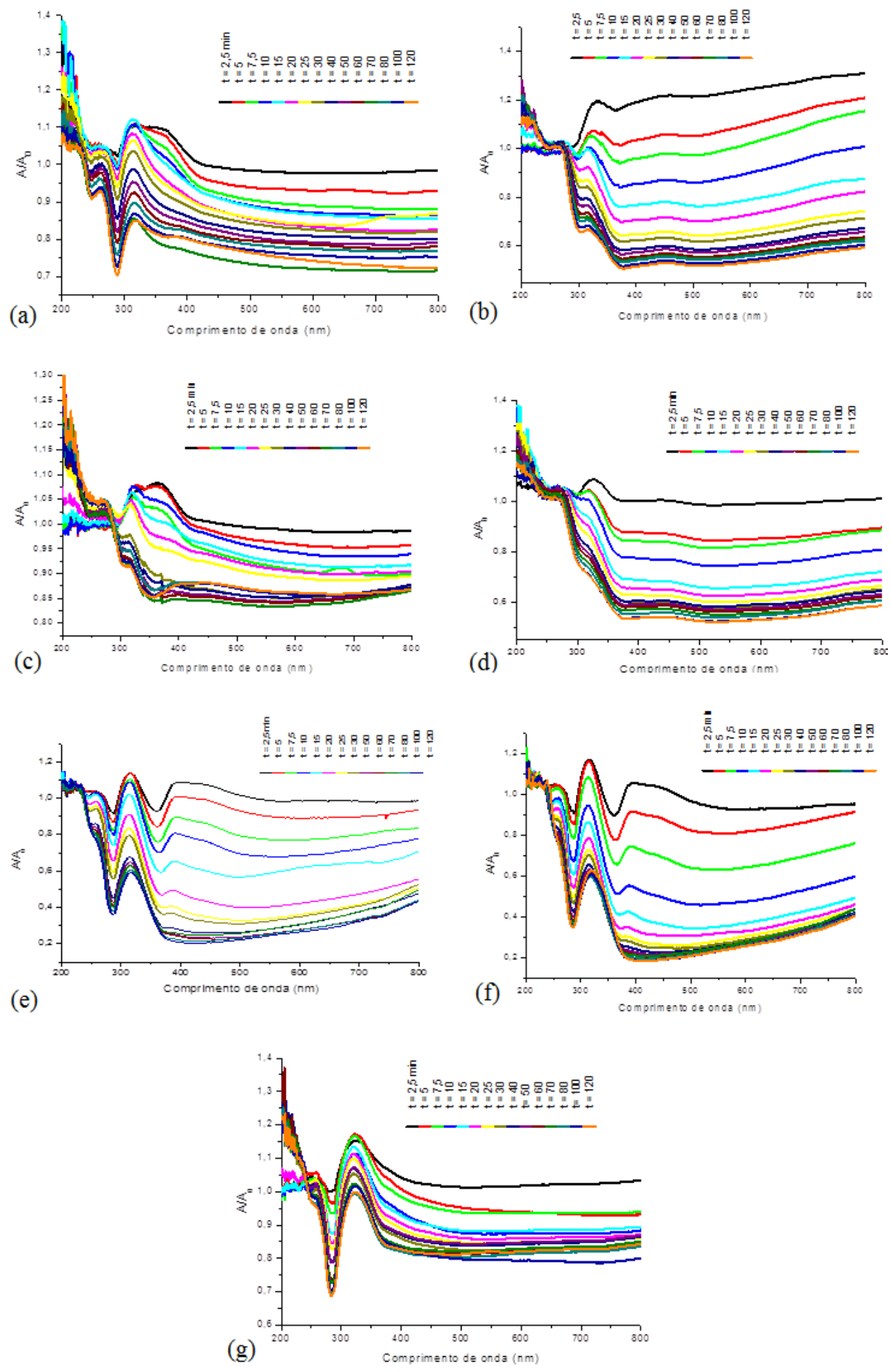
Pôde-se observar que o sistema $\mathrm{pH}$ 6,0 e $\left[\mathrm{O}_{3}\right]=30 \%$ alcançou a menor relação $\mathrm{A} / \mathrm{A}_{0}$ final. Como esperado, menores concentrações de ozônio e $\mathrm{pH}$ não foram efetivas na redução deste parâmetro. É possível que em pH 6,0 houve competição dos dois mecanismos de reação de ozônio (direto e indireto), indicada pela diferença na relação $\mathrm{A} / \mathrm{A}_{0}$ aos 5 minutos e 120 minutos, apresentando maior degradação.

\section{CONCLUSÃO}

A aplicação da ozonização mostrou-se eficiente na redução de cor do efluente e da turbidez (que chegou a 85\%). Entretanto, como a carga orgânica inicial era muito alta, sua redução só foi expressiva em dois experimentos, ambos pontos centrais, que apresentaram de redução de 35 e $53 \%$. A amostra que aliou bons desempenhos em todos os parâmetros foi a amostra 6, que reduziu a turbidez em $78,6 \%$ e a DQO em $53 \%$.

\section{REFERENCIAS}

ALMEIDA, E. S.; ASSALIN, M. R.; ROSA, M. A. Tratamento de efluentes industriais por processos oxidativos na presença de ozônio. Quím. Nova, v. 27, n. 5, p. 818-824, 2004.

APHA (1998). Standard methods for the examination of water and wastewater. 20a edição. Washington:APHA/AWWA.

CEREDA, M. P. Caracterização dos Subprodutos da Industrialização da Mandioca. IN: Cereda, M. P. (Coord.) Manejo, uso e tratamento de subprodutos da industrialização da mandioca. São Paulo: Fundação Cargill, 2001, (Culturas de Tuberosas Amiláceas Latino Americanas, 4V, Cap.01, p. 13- 37).

FIOREZE, M., SANTOS, E. P., SCHMACHTENBERG, N. Processos oxidativos avançados: fundamento e aplicação ambiental. REGET, v. 18, n. 1, p. 79-91, 2014.

KUCZMAN, O.; TAVARES, F. H. M; GOMES, D. S. Tratamento anaeróbio de efluente de fecularia em reator horizontal de uma fase. Dissertação de mestrado. UNIOESTE, 2007.

MELO, S. A. S.; TROVÓ, A. G.; BAUTITZ, I. R.; NOGUEIRA, R. F. P. Degradação de fármacos residuais por processos oxidativos avançados. Quím. Nova, v. 32, n. 1, p. 188-197, 2009.

NASU, E. G. C.; PIRES, E.; FORMENTINI, H. M.; FURLANETTO, C. Efeito de manipueira sobre Meloidogyne incognita em ensaios in vitro e em tomateiros em casa de vegetação. Trop. Plant Path., v. 35, n. 1, p. 32-36, 2010.

SOUZA, S. O.; OLIVEIRA, L. C.; CAVAGIS, A. D. M.; BOTERO, W. G. Cyanogenic residues: environmental impacts, complexation with humic substances, and possible application as biofertilizer. Water, Air \& Soil Pollut., v. 225, p. 1-13, 2014. 